\title{
Volunteer vs. Professional Community Translation in Video Game Localization: The Case of the Steam Translation Server in Turkish
}

\author{
Semih SARIGÜL* and Jonathan Maurice ROSS**
}

In the last two decades, audiovisual translation has come to be employed in an ever-widening range of contexts and media, an expansion which has been more or less reflected in research. Meanwhile, video game localization and the volunteer translation communities responsible for it have become popular research topics around the world. In Turkey, despite the existence of both volunteer communities and professional localization companies, academic studies on video game localization are scarce. To help fill this gap in the literature, the present study ${ }^{1}$ aims to explore the potential similarities and differences between community translation processes in volunteer and professional video game localization in Turkey. To this end, two group interviews were carried out: one with members of a volunteer video game localization community operating within the Steam Translation Server, the other with the representatives of a professional localization company in Istanbul, Turkey. The localization processes reported by the respondents were compared in the light of the typologies and processes of community translation presented in the literature. The findings from the interviews indicated that the video game localization processes followed by the two communities resembled one another in terms of management, participation, and closed community structure, but the volunteer community sometimes displayed more flexibility in these aspects and did not seem to set such strict standards. The findings thus suggest that theories of community translation need to take more account of both common and distinguishing features of online communities and offer new categorizations for blended community structures.

Keywords: audiovisual translation; video game localization; community translation; volunteer translation; the Steam Translation Server

\section{Introduction}

Since the scope of audiovisual translation (AVT) has broadened in recent years, the field is no longer considered to comprise cinema and TV alone. Research on AVT now also deals with different multimedia products and semiotic modes such as video game localization (VGL),

\footnotetext{
* Lecturer at Kahramanmaraş Sütçü İmam University.

E-mail: semihsarigul@ksu.edu.tr; ORCID ID: https://orcid.org/0000-0002-8691-0202.

** Assistant professor at Boğaziçi University, Istanbul.

E-mail: jonathan.ross@boun.edu.tr; ORCID ID: https://orcid.org/0000-0002-2537-8582.

(Received 16 October 2020; accepted 3 December 2020)

${ }^{1}$ This paper derives from the primary researcher's PhD dissertation at Boğaziçi University, Istanbul, on video game localization in the Steam Translation Server in Turkey.
} 
transLogos 2020 Vol 3 Issue 2

Sarıül, Semih, and Jonathan Maurice Ross, pp. 1-22

Volunteer vs. Professional Community Translation in

opera surtitling, or audio description (O'Hagan 2012, 127-128). Although, until the 2000s, VGL was not studied within the framework of AVT, it has now been accepted as an established element in this field (Pérez González 2009, 13; Hernández Bartolomé and Mendiluce Cabrera 2005, 91). Points of overlap between AVT and VGL include the presence of cinematic sequences, the use of subtitling and dubbing, the importance of cultural issues, and the existence of similar translation processes. These and other dimensions make VGL a suitable field of research within the framework of AVT.

Despite the growing popularity of VGL in academic research around the world, the number of studies on the topic in Turkey is relatively low; such studies date back to only 2015 (Odacıŏlu and Köktürk 2015; Önen 2018; Zan 2018; Diri 2019; Karagöz 2019; Öncü Y1lmaz and Canbaz 2019; Sarıül 2020). Video games localized into Turkish have not attracted the attention they deserve from translation scholars in Turkey, whereas there are many studies on VGL in languages such as Czech, Dutch, Finnish, Japanese, Persian, Portuguese, and Spanish. In addition, although online platforms and mass media devices occupy a critical position in VGL activities, particularly in voluntary ones, these activities have rarely been addressed from the viewpoint of community translation, except in a few studies (Muñoz Sánchez 2009; Petrů 2011; O’Hagan and Mangiron 2013; Galhardi 2014; Odac1oğlu and Köktürk 2015). Finally, although Steam is one of the most widely used video game platforms across the world, offering VGL performed by its volunteer users, very limited attention has been paid to the VGL activities undertaken by Steam's volunteer translation platform, the Steam Translation Server (STS). The STS has been mentioned in only a handful of studies (Koelewijn 2015).

To fill the abovementioned gaps in the current VGL literature, the present study attempts to add another link to the short chain of studies on VGL in Turkey by analyzing on the one hand the STS and Turkish Translation Community (TTC), a volunteer VGL community within the STS, and on the other hand 23Studios, a professional VGL service company in Istanbul, Turkey. The study attempts to shed some light on the similarities and differences between volunteer and professional community translation processes in VGL from English into Turkish within the context of the STS. It also aims to investigate the extent to which community translation processes govern VGL activities in TTC and 23Studios (i.e., in volunteer and professional contexts), respectively. For this purpose, interviews were conducted with project managers and 
transLogos 2020 Vol 3 Issue 2

Sarıül, Semih, and Jonathan Maurice Ross, pp. 1-22

Volunteer vs. Professional Community Translation in

translators at TTC and 23Studios, with the focus being on their community translation models and their distinct organizational features.

\subsection{The Steam Translation Server}

Running since December 2003, Steam is a digital video game distribution platform owned by Valve Corporation. It distributes legal digital copies of games and automatically updates them if necessary. Its primary objective is to offer low-cost video games for users around the world, thereby preventing video game piracy. In 2007, it introduced its 'community' function, making it possible for Steam users to create their own online communities for any video game, so that they could chat with their friends and other players and/or exchange information/feedback on any video game sold by Steam. These communities are also venues for multiplayer video games, in which users play against other people around the world. Therefore, Steam can be considered as an online video game world which, in addition to selling inexpensive video games, addresses video game players' various needs. As it offers video games for all operating systems (e.g., Windows, Mac, Linux), it has rapidly become popular among video gaming communities around the world. ${ }^{2}$

In 2010, Steam introduced the STS in order to provide 125 million active Steam users with VGL for the video games sold in its official online market. Currently, it offers VGL for various video game genres in 26 different languages and invites all volunteering Steam users to submit their translations by logging in to the STS using their personal Steam accounts. These volunteer translators are also allowed to check other volunteer translators' suggestions and provide feedback on them by voting or commenting if necessary. In addition, active translators and proofreaders can be promoted to the status of language community moderator if they are designated 'successful' by other volunteer translators in the same community. All contributions to the STS are "entirely voluntary." Although it is possible for volunteer STS translators to translate from more than one language, the STS strongly advises its members to focus on two main languages, which are usually English and the member's mother tongue. Thus, it encourages its members to be specialized in a specific language, thereby creating higher quality VGL. Thanks to the participation of new translator-users, the spectrum of languages in the STS is constantly increasing. For each language, there can be multiple communities of translator-

\footnotetext{
2 “About Steam,” Steam, accessed October 15, 2020, http://store.steampowered.com/about/.
} 
transLogos 2020 Vol 3 Issue 2

Sarıül, Semih, and Jonathan Maurice Ross, pp. 1-22

Volunteer vs. Professional Community Translation in

users. The moderators of each community working on a certain language are responsible for the review and approval of translations submitted by the members of that community. ${ }^{3}$

\subsection{Turkish Translation Community}

TTC is the most popular and largest volunteer community in the STS working on VGL from English into Turkish. The community has been actively localizing video games since 2012 and is one of the few language communities in the STS which have completed the localization of nearly $99 \%$ of all video game content available to them. As of early 2020, TTC had 219 actively translating members, and the community moderators emphasize that only Steam users who will actively and regularly contribute to the community are allowed to participate and remain in the group. In other words, those who rarely translate for the community (usually less than twice a year) are dismissed without any prior notice. ${ }^{4}$ Similar to other communities in the STS, TTC conducts all of its activities on a voluntary basis. As such, it can be considered a solid example of community translation-based volunteer VGL in Turkey.

\subsection{Studios}

23Studios is a professional localization service company that has been running in Istanbul since 2009. In addition to producing VGL for leading video game publishing companies in the US and Europe and online platforms such as the STS, the company offers various localization-related services such as audio localization or quality assurance in localization. The company currently employs 60 salaried and freelance translators and VGL experts from different professional and educational backgrounds who came together due to their "love for games" and are motivated by a "shared purpose." 23Studios mainly focuses on the Turkish VGL market. However, apart from conducting its professional VGL activities, the company also continues to develop its own video games. In this respect, it claims to be "wired ... into the heart of Turkish digital gaming ecosystem" thanks to its role in bringing video game publishing companies and players together. This helps it understand the needs of both video

\footnotetext{
3 "Introduction to the Steam Translation Server," Steam, accessed October 15, 2020, https://steamcommunity.com/sharedfiles/filedetails/?id=171054487.

4 "Üye Listesi Temizliği"" (Member list clearance), Steam, accessed October 15, 2020, https://steamcommunity.com/groups/TurkishTranslations/announcements/detail/92688143662514349.
} 
transLogos 2020 Vol 3 Issue 2

Sarıül, Semih, and Jonathan Maurice Ross, pp. 1-22

Volunteer vs. Professional Community Translation in

game developers and the target audience. ${ }^{5} 23$ Studios' portfolio and its experience of providing VGL for several well-known companies in the global video game industry make it one of the most important players in the Turkish VGL sector. Thus, it is a potentially fruitful case through which one can compare a professional, community translation-based VGL process in Turkey with the voluntary process undertaken within the STS.

\section{Conceptual Framework: Community Translation}

Community translation is defined as a practice "whereby non-professionals translate software or websites that they actually use" (Pym 2011, 79), with "non-professionals" denoting various online communities on the Internet. It is often assumed that such communities are made up of anonymous users, but the concept of community translation can be understood as referring to a group of people serving a certain community or organization and granted a certain degree of access to, and participation in, the translation processes within that community or organization (Jiménez Crespo 2017, 30). Another assumption about community translation is that it is similar to community interpreting, in which bilingual volunteers or paid professionals serve as interpreters in public institutions (26). Minako O'Hagan (2011, 12-13) recognizes that even though the two are conceptually similar, community translation is often heavily intertwined with online collaborative translation activity.

Nataly Kelly, Rebecca Ray, and Donald A. DePalma $(2011,77)$ broadened the concept of community translation so that it could encompass the work of volunteers, employees, and professional translators, or a hybrid group combining such agents. The term is a concise and handy way of labelling what had previously been referred to as the process of translate-editpublish, with the advantage that it enables these three tasks to be conceptualized as a single unit (77-78). Kelly, Ray, and DePalma's model of community translation views a localization project as a task usually managed and supervised by a project manager acting as the initiator of that project. This manager supplies the files to be translated, creates a terminological database, and invites translators who are willing to take part in the "project community," which is a team of translators, proofreaders, editors, and publishing company staff (77). The project manager can be considered as a 'facilitator' for the community rather than as a boss who orders subordinates to complete a given task. The manager will often set up the translation community,

\footnotetext{
5 “About Us," 23Studios, accessed October 15, 2020, https://23studios.org/about-us/.
} 
transLogos 2020 Vol 3 Issue 2

Sarıül, Semih, and Jonathan Maurice Ross, pp. 1-22

Volunteer vs. Professional Community Translation in

provide its members with necessary resources for the ongoing project, and motivate them, enabling them to contribute to the project (79). Additionally, the manager may invite specialists working in a certain field to the community for an exchange of ideas about the project and give the community members an opportunity to revise their work based on the specialists' views (78).

The community sometimes functions in an asynchronous manner, as some translators may complete a certain part of the project in a few days while others may take a few weeks to fulfil a similar task. Sometimes, one member in the community may also intervene in other members' work to suggest improvements or changes to the existing translations, which helps the community correct errors soon after they are made (Kelly, Ray, and DePalma 2011, 78). One of the benefits of community translation is that, in order to reduce the amount of translation problems waiting for final review, timely solutions can be offered to an existing problem by a community member. This is ensured through means of communication such as instant messaging and video conferencing (85). To this end, community members are always encouraged to ask questions in an online environment such as a forum or website and they receive feedback on their suggested translations or any other technical problems they face. People who use the service translated or localized by the community in question may also contribute to the community members' work through their comments on the product or service (81). In this way, community translation allows multiple parties to contribute to the completion of a translation project in the easiest way and shortest time possible.

Kelly, Ray, and DePalma (2011) delineate three different community translation environments: wiki- or forum-based, database-driven, and full-blown. The first category refers to simple community translation environments, controlled by a single moderator or a few moderators, involving the use of a simple software or forum. The second category is identified as the most commonly used environment, providing community members with an interface or a technically-supported dashboard by means of which they can participate in the community translation process. Finally, full-fledged environments are far less common than the other two categories due to the investment costs they entail. This model serves crowdsourcing projects rather than community translation, and translators are provided with terminological assistance and memory tools as well as access to machine translation (90). 
transLogos 2020 Vol 3 Issue 2

Sarıül, Semih, and Jonathan Maurice Ross, pp. 1-22

Volunteer vs. Professional Community Translation in

Projects undertaken by TTC and 23Studios are supervised by a project manager who also contributes actively to the translation process by means of various online facilities. Where the two organizations obviously differ is that the TTC is a voluntary online community, while 23Studios carries out its projects with the aim of accruing income. As shall be demonstrated, a closer analysis of the processes followed by these two organizations in their VGL projects encourages us to reflect on the validity of Kelly, Ray, and DePalma's (2011) tripartite categorization and to ponder the utility of the broad notion of community translation.

\section{Methodology}

\subsection{Method: Group Interviews}

The interviews with TTC and 23Studios were designed to be group discussions, as more than one member of each of these two organizations was requested to take part in the present study. The reason why this was preferred instead of a one-on-one interview is that the group interview method was held to be more likely to reveal the level of interactivity in both communities and enable participants to contribute to and/or build upon other participants' views (Edley and Litosseliti 2010, 167). Both interviews were conducted on a semi-structured basis to create a more natural flow of discussion and to allow for the emergence of topics that had not been envisaged in the researcher's questions. Although both interviews were actually planned as focus groups, they were later turned into group interviews due to the relatively low number of participants.

\subsection{Participants}

A purposive sampling method was used to select eligible participants. We chose to focus on TTC as an organization because it appeared to exemplify the phenomenon of volunteer community translation. At the beginning of the study, the moderator of TTC, MAG, ${ }^{6}$ was contacted by e-mail and asked a few questions to clarify the structure of TTC and his role in the community. He was also asked whether he would be willing to participate in the interview, which he gladly accepted to do. Afterwards, he was requested to give the names and contact details of some other volunteering group members. This was supposed to ensure that other

\footnotetext{
${ }^{6}$ The participants are referred to by the initials of their names for confidentiality.
} 
transLogos 2020 Vol 3 Issue 2

Sarıül, Semih, and Jonathan Maurice Ross, pp. 1-22

Volunteer vs. Professional Community Translation in

potential participants would be credible and qualified enough to contribute to the present study, since they had been recommended by the community moderator. The following day, another group member, MAK, was contacted and asked if he would like to be included in the study. MAK also agreed. A third group member mentioned by MAG, BK, stated that he was unwilling to take part, so we were left with two respondents who were active group members. As MAG stated that he did not personally know other active group members and could not vouch for their quality as interviewees, it was decided to limit the number of interviewees in TTC to just two (i.e., the community moderator and an active translating member).

The purposive sampling method was used to select participants for the interview with 23Studios too. An e-mail was sent to 23 Studios to ask the senior manager whether he and other members of the company could be interviewed for this research. The senior manager contacted two other permanent translators working for the company, who are also project managers, to request their participation, and they both consented. As a result, the respondents from 23Studios turned out to be three permanent 23Studios employees: a senior manager (i.e., OE) and two project managers also working as translators (i.e., ACC and GHD). The credibility of the latter two participants was ensured by the senior manager of 23Studios, in that both of them had taken active roles in all stages of the company's VGL projects.

Gabriela Saldanha and Sharon O'Brien $(2013,182)$ advise translation studies researchers to include at least six participants in focus group interviews in order to ensure fruitful discussion. However, it could be argued that just two participants from TTC and three participants from 23Studios would be sufficient for this research on community translation processes. This is because the interviewees included the most authoritative figures in both communities (i.e., one senior manager and two other project managers), as well as an active member in TTC and two permanent employees of 23Studios. The reason why the translators were invited along with project managers was to gain some insight 'from below.' All parties were well-informed about the VGL processes in their respective communities.

\subsection{Structure of the Interviews}

Eighteen questions were prepared for use in both interviews, the authors discussing and drafting the questions together before arriving at the final version. The questions were divided into two different categories. The first category included personal questions concerning 
transLogos 2020 Vol 3 Issue 2

Sarıül, Semih, and Jonathan Maurice Ross, pp. 1-22

Volunteer vs. Professional Community Translation in

participants' age, level of education, field of education, and the cause of their interest in VGL. The second category sought answers to the details of community translation in TTC and 23Studios. It attempted to explore how the project manager/moderator assembles their community, how they manage the division of labor in the community, how community members communicate with each other during the VGL process, which technological and translation tools they use to fulfil their tasks, how they make decisions about controversial topics, and how they test and check localized textual segments in the localization testing process. There were also questions about the community's relationship with the STS and Valve.

Although participants were reminded of the importance of giving direct answers, they were also encouraged to deviate from the main question and add details that would enrich the discussion and offer fruitful contributions to the study. If necessary, the wording of questions was changed to make them clearer for the participants. Some statements by the participants were repeated by the interviewer (the primary researcher) to fully understand what they meant by a word, sentence, or statement. However, the interviewer avoided leading participants towards a certain view about any question. Apart from the main questions, some follow-up questions were asked during the interviews to gain further insight into what participants underlined about an aspect of community translation. In addition, at the end of each interview, the participants were invited to make further comments about any points that had not been raised during the interviews.

\subsection{Data Collection}

Following the selection of participants, they were asked to sign a consent form to demonstrate that they were willingly participating in, and had received sufficient information about, the present study. Later, participants from both communities were invited for two separate online interviews at a date and time suitable for them. The interview was conducted using a video conferencing software, as the researchers and participants were located in different cities. However, during the interviews, the participants were together with their fellow community members and colleagues.

Both interviews were recorded using the video conferencing software and later downloaded to the primary researcher's personal computer. To avoid any misunderstandings, all participants were informed beforehand that the discussions were going to be recorded and 
transLogos 2020 Vol 3 Issue 2

Sarıül, Semih, and Jonathan Maurice Ross, pp. 1-22

Volunteer vs. Professional Community Translation in

were given the opportunity to download a copy of their own interview. In addition, they were also reminded of their rights to withdraw from the interview at any point or withhold information that would violate any of the previously signed non-disclosure agreements and leave them in a legally difficult situation. It was also guaranteed that the recorded interviews would be kept confidential and participants' names would be mentioned by coding their initials. At the beginning of the interviews, the purposes of the present study were briefly described to enlighten all participants about what they were going to talk about. Both interviews were conducted in Turkish and took 55 and 65 minutes, respectively. They were later transcribed word-for-word for data analysis.

\section{Results}

4.1 The Community Translation Process in Video Game Localization in Turkish Translation Community

The interview with TTC revealed that the community displayed several of the previously identified attributes of community translation. Firstly, this community is managed by a moderator who has acted as a project manager through creating the community and establishing communication among community members ever since early 2014. MAG's facilitating role in the community is manifested by the STS Translation Guide, which he published on the official page of TTC in the STS. In this guide consisting of four sections, MAG informs newly registered volunteer translators in the STS about contributing to the localization projects, warns them about various common syntactic, grammatical, and punctuation mistakes during the translation, and underlines the critical role of textual integrity. In the second section, he explains how textual segments in the STS are classified into three priority categories based on their importance for the VGL project and asks translators to comply with this procedure unless specified otherwise. In the third section of the guide, MAG answers frequently asked questions about how to become a member of TTC and how to offer translations for any textual segments in the STS. In addition, he teaches new members how to track their own suggested translations and clarifies the process by which a new member's suggested translation is approved or corrected by the moderator. In the final section of the guide, MAG 
transLogos 2020 Vol 3 Issue 2

Sarıül, Semih, and Jonathan Maurice Ross, pp. 1-22

Volunteer vs. Professional Community Translation in

recommends translators different tools such as online dictionaries and translation memory tools that will help them and enable them to maintain terminological consistency. ${ }^{7}$

This guide indicates that MAG fulfils nearly all the roles expected of a project manager in a community translation process, as described by Kelly, Ray, and DePalma (2011). For instance, in order to initiate the VGL process, he invites new volunteers to the community. He also creates the list of textual files to be translated based on their degree of importance, which can be categorized as an attempt to create a textual database. In addition, he offers different resources to the members, such as lesser-known translation memory tools or terminologyspecific online dictionaries. Therefore, he can be considered as a typical project manager observed in community translation processes.

Despite being the coordinator of activities in TTC, MAG clearly stated in the interview that his position as the project manager did not mean that there was a hierarchical structure within the community. If necessary, he brings together group members who live in the same city or organizes a video conference. During these meetings, he asks members which textual files they would like to or can translate. However, the files are always shared among community members, and a TTC member including the moderator himself may undertake to translate another member's assigned file in case of any force majeure. When the community members cannot find sufficient time to organize face-to-face meetings, they also frequently benefit from instant messaging applications to quickly organize the division of labor among themselves. However, MAG stated that the frequency of their meeting dates often varied depending on the size of text files waiting to be translated within a specific period of time. When there are no new updated files for VGL, the community might not hold a meeting for a couple of months.

Another indicator of equality among TTC members is the way in which they approach other members' or the moderator's suggested translations. MAG stated that he/TTC always encouraged all community members to propose equivalents for problematic words or phrases and that all suggestions were taken seriously without any prejudice. In addition, members are requested not to hesitate to comment on each other's work and to pinpoint any mistakes in other members' suggested translations. This tendency can be witnessed in some discussion topics posted on the official page of the community, where a user asks whether or not their translation

\footnotetext{
7 "STS Üzerinde Çeviri Yapma Rehberi” (STS translation guide), Steam, accessed October 15, 2020, https://steamcommunity.com/groups/TurkishTranslations/discussions/0/527274088387250726.
} 
transLogos 2020 Vol 3 Issue 2

Sarıül, Semih, and Jonathan Maurice Ross, pp. 1-22

Volunteer vs. Professional Community Translation in

is suitable. ${ }^{8}$ In addition to accepting intra-community criticism, TTC members also take into account Steam users' comments on various translation mistakes or suggestions for better equivalents and view them as opportunities to revise recently submitted translations immediately. According to MAG, this is vital in their VGL projects, since the number of new textual files is unlimited for a constantly updated video game such as Dota 2, a multiplayer online video game, forever giving rise to new discussion topics around terminological problems in new textual segments. Both MAG and MAK stated that such an open, critical approach strengthened translators' beliefs in the quality of their translations and increased the coordination among community members. They added that they had always been happy to be a part of this thought-provoking environment.

Video game publishing companies are also known to occupy an important place in community translation processes because of copyrights. They possess the privilege to direct translators sometimes, even if they are only volunteers. Although all TTC members are volunteers and do not receive any financial payments from Valve or the STS, they still need to pay attention to the authoritative position of the company. However, MAG and MAK stated that they did not face any pressure from publishers regarding the submission deadline of a textual segment or file, and they noted that the company did not intervene in translation decisions of the community. According to MAG, this flexibility can be attributed to the fact that they have worked with Valve for a long time and are trusted by the company in terms of their credentials as a volunteer translation community. As they are not usually forced to submit their translations on a certain date, individual community members may complete their share of textual files on different dates, which can be considered as a feature of asynchronous functioning in community translation.

Kelly, Ray, and DePalma (2011) consider the participation of specialists outside the community to be one of the distinctive features of a community translation project. However, MAG stated that they could not include any other person outside the community due to the fact that they accepted a non-disclosure agreement at the beginning of registration in the STS. Although it is sometimes possible for them to consult someone specialized in a certain field about a certain term or phrase, they are not often allowed to share longer textual segments with

\footnotetext{
8 "Çevirim Sizce Yanlış mı?" (Do you think my translation is wrong?), Steam, accessed October 15, 2020, https://steamcommunity.com/groups/TurkishTranslations/discussions/0/1489992713709179288.
} 
transLogos 2020 Vol 3 Issue 2

Sarıül, Semih, and Jonathan Maurice Ross, pp. 1-22

Volunteer vs. Professional Community Translation in

any individual who is not a registered volunteer translator in the STS, as this would mean violating the non-disclosure agreement.

In the light of these findings, it can be argued that both the wiki-based and databasedriven community translation models (Kelly, Ray, and DePalma 2011) are apt for characterizing the community translation process in TTC during a VGL project. TTC conforms to the former category in that it is controlled by a single community moderator and offers a simple forum consisting of a straightforward homepage and a discussion board. However, it can also be classified under the latter category, since it functions within the environment of the STS, which provides all volunteer community members with a technically supported platform to complete translations online. Therefore, TTC can be regarded as a mixture of both community translation models and thus represents an interesting case of VGL practice in Turkey.

\subsection{The Community Translation Process in Video Game Localization in 23Studios}

23Studios can be viewed as another representative example of community translation, which differs from TTC, however, due to its professional structure. This requires the company to plan the distribution of labor in the project team more meticulously, so as to minimize potential problems and submit the completed project on time. This can also be attributed to the fact that 23 Studios will be held responsible and accountable by the video game publishing company.

Although Kelly, Ray, and DePalma (2011) emphasize project managers' coordinating and integrating role in community translation projects, rather than describing them as authoritarian bosses, 23Studios displays a hierarchical structure to some extent, particularly as far as the distribution of labor among employees is concerned. OE stated that it was always project managers at 23 Studios who divided textual segments to be translated into different parts and made decisions regarding how many textual segments a project member would undertake within a specific period of time. Similarly, freelance translators are not often given the right to select a certain textual segment depending on their interest in different parts of a video game. According to $\mathrm{OE}$, the strictness of this policy stems from the fact that some video game publishing companies do not send them textual segments to be translated as a whole, and they sometimes receive a high number of textual segments that cannot be handled without detailed 
transLogos 2020 Vol 3 Issue 2

Sarıül, Semih, and Jonathan Maurice Ross, pp. 1-22

Volunteer vs. Professional Community Translation in

project management. In such an environment, OE added, allowing translators to choose their own texts might cause a crisis in the VGL process, as well as further delays in the project deadline. According to ACC, another reason why 23Studios attaches particular importance to the distribution of textual segments is their eagerness to preserve the textual integrity of the video game. Because a typical episodic video game often involves numerous missions which are coherently combined to narrate a certain storyline, it is of vital importance for ACC and GHD to allocate each mission to a particular community member to prevent any terminological, syntactical, or rhetorical inconsistency in the localized version. In parallel with the theoretical definition of community translation, GHD stated that this demanding task was exactly what 23Studios expected from them as project managers.

Another indicator of a more hierarchical community translation process in 23Studios is the fact that some translators in the project team are only assigned to proofread and edit translated segments of a video game, without any intervention in the actual localization process. ACC stated that while nine translators actively participated in the localization stage of a video game, three translators were engaged in the "quality control" of translated materials. According to GHD, this strategy was used to assign certain tasks to particular project members, in an attempt to avoid misunderstandings or prevent any task-related crisis in a VGL project.

The community manager's role of providing the translators with relevant sources and tools that will help them in the localization process is also fulfilled by ACC and GHD in 23Studios. For instance, ACC stated that they always prepared an online glossary in an Excel file, which included key terms that translators were likely to encounter in the textual segments. Unlike the distribution of textual segments 'from above,' this glossary preparation reflects a much more democratic and participatory approach, since discussions do take place about different options for a given term in a video game. ACC stressed that any member of the project community in a VGL process, be it the senior manager, project managers, a translator, or an editor, was free to suggest a Turkish equivalent for a given term in a video game, provided that his/her proposal conformed to grammatical rules and daily use of Turkish. Thus, 23Studios gives each employee the opportunity to clearly express their opinions on potential equivalents that will be used throughout the project. However, they usually exchange ideas about these problems through video conference or in one-on-one instant messaging sessions among the 
transLogos 2020 Vol 3 Issue 2

Sarıül, Semih, and Jonathan Maurice Ross, pp. 1-22

Volunteer vs. Professional Community Translation in

company's translators and project managers. They do not have recourse to an open-access online forum like the pages of volunteer communities in the STS.

According to $\mathrm{OE}$, if project members' proposals were restricted by senior or project managers, they would miss the chance to find a "suitable" equivalent for a challenging term, which would eventually reduce the quality of their work. GHD added that, even after the project team decided to use a certain equivalent for a certain term in the source text, they always continued to encourage all project members to give feedback on potential new equivalents which could improve the localized version. As a result, such glossaries usually undergo extensive revisions until the VGL project is finished. These interactive discussions taking place in the office or on an online messaging and video conferencing service largely overlap with the participative environment described by Kelly, Ray, and DePalma (2011).

The community translation process in 23 Studios is shaped by the deadlines set by video game publishing companies. ACC underlined the vital role of deadlines in their VGL projects due to intricate details such as font design or video game equipment testing. GHD also stated that the deadline of a VGL project occupied a central position in the whole VGL process, and all other activities were scheduled and performed based on the last date for the submission of the localized version of a video game. All participants found such an approach inescapable, as video game publishing companies aim to localize their products in several languages and need to complete all localization projects on time, including the testing process. Nevertheless, 23Studios' views on a suitable deadline are still taken into account by the commissioning video game companies if the company insists on a longer project duration to achieve higher VGL quality. In other words, project managers usually try to find a balance between the commissioner's needs and the technical and professional capacity of their company and team.

As for external contributions to their VGL projects, all participants stated that the company could not include any other translators or specialists as advisory support due to the potential sanctions which would be imposed owing to their extensive non-disclosure agreements. When asked whether they could consult someone specialized in the field of translation or VGL about a certain word, phrase, or translation strategy, OE answered in the negative and stated that the company could not risk releasing even the most seemingly insignificant information. Nevertheless, in the case of some exceptional situations, they may 
transLogos 2020 Vol 3 Issue 2

Sarıül, Semih, and Jonathan Maurice Ross, pp. 1-22

Volunteer vs. Professional Community Translation in

ask the video game publishing company to allow them to hire a freelance coworker, who would again join the project team after signing a non-disclosure agreement with 23 Studios.

Community translation activities in 23Studios cannot be considered as taking place in a wiki-based environment, because they do not revolve around a simple forum. Instead, they function in a closed system, which cannot be freely accessed. Neither do they represent a database-driven community translation environment, since the company does not use a specific online interface for community discussions but rather benefits from video conferencing and instant messaging applications. Therefore, this localization service company conforms to the third category (i.e., a full-fledged community translation environment) (Kelly, Ray, and DePalma 2011). Indeed, OE stated that 23Studios invested in their infrastructure to the extent that it would be in a position to carry out its own dubbing for VGL projects. In addition, it provides its permanent and freelance staff of translators with its own terminology management and translation memory tools and can integrate these systems into any project that it undertakes. Therefore, 23Studios can be categorized as an exemplar of full-fledged community translation, one which differs from TTC on a number of counts.

\section{Discussion}

It can be inferred from both the results reported above and from Table 1 below that, while the community translation undertaken by TTC and by 23 Studios have some points in common, they also display no less significant differences.

Table 1. A comparison of the community translation activities in TTC and 23Studios

\begin{tabular}{|l|l|l|l|}
\cline { 2 - 4 } \multicolumn{5}{c|}{} & \multicolumn{1}{c|}{ TTC } & \multicolumn{1}{c|}{ 23Studios } \\
\hline \multirow{5}{*}{ Community translation } & Project manager & Less authoritative & More authoritative \\
\cline { 2 - 4 } & Hierarchy & Less hierarchical & More hierarchical \\
\cline { 2 - 4 } & $\begin{array}{l}\text { Discussion on } \\
\text { equivalents }\end{array}$ & $\begin{array}{l}\text { Democratic and } \\
\text { participatory }\end{array}$ & $\begin{array}{l}\text { Democratic and } \\
\text { participatory }\end{array}$ \\
\cline { 2 - 4 } & Project deadlines & No deadlines & Strict deadlines \\
\cline { 2 - 4 } & $\begin{array}{l}\text { Participation of } \\
\text { external individuals }\end{array}$ & Occasionally & Never \\
\cline { 2 - 4 } & Process model & $\begin{array}{l}\text { Wiki-based and } \\
\text { database-driven }\end{array}$ & Full-fledged \\
\hline
\end{tabular}

The first striking similarity between the two groups in terms of community translation is the crucial role of project managers for VGL. Although TTC members prefer to use the term 
transLogos 2020 Vol 3 Issue 2

Sarıül, Semih, and Jonathan Maurice Ross, pp. 1-22

Volunteer vs. Professional Community Translation in

'group moderator' rather than 'project manager' to label the person who is in charge of group activities, MAG in TTC and ACC and GHD in 23Studios fulfil similar roles, because they bring project members together and organize the distribution of textual segments among project members. However, the latter function is carried out differently by the two groups. The distribution of textual segments is left to the choices of group members in TTC, whereas it is ACC and GHD who determine each member's tasks in a VGL project in 23Studios. In addition to this, while all TTC members are free to undertake any other member's task if necessary, to clarify the flow of a VGL project, 23Studios gives members clearly defined positions such as 'translator' or 'editor.' These examples indicate that 23 Studios exhibits a more hierarchical structure in terms of VGL project management. This difference is likely to result from the fact that TTC is a volunteer translation group and thus cannot expect any person in the group to carry out a pre-defined task, while 23Studios is a profit-seeking VGL service company and has the right to ask its employees to fulfil a certain task in return for their salary and/or payments.

It was found in the interviews that the discussion of VGL strategies or the choice of specific terms in a textual segment gave rise to a democratic and participatory environment in TTC and 23Studios. Both groups value each member's opinion on a given controversial term or phrase, in the hope that the best Turkish equivalent for an English term can be found or creative strategies can be developed for a specific problem. Therefore, it can be suggested that in both groups the practice of community translation for VGL projects boosts the attempt to generate consensus and nurtures the idea that all participants in a VGL project, be they volunteers or paid professionals, are equal members of a community. However, a slight difference can still be observed. While TTC is more open to accepting community members' individual suggestions, 23Studios usually expects its members to justify their proposals on a more solid ground, to ensure that they select the best option from among a few alternatives and to ensure a higher quality of VGL. Again, in the case of 23Studios, the pressures imposed by a professional environment lead to a more rigorous decision-making procedure.

Although both groups' members agree that they need to take the video game publishing company into account, it is evident that 23Studios encounters more pressures compared to TTC. This is because its members have to complete their assigned tasks according to a specified deadline, and it is this emphasis on scheduling that characterizes the company's community translation process. On the other hand, apart from a few exceptions, TTC members usually 
transLogos 2020 Vol 3 Issue 2

Sarıül, Semih, and Jonathan Maurice Ross, pp. 1-22

Volunteer vs. Professional Community Translation in

perform their VGL activities under less strict time constraints, and they can submit localized textual segments whenever they finish them. Such a difference is likely to arise from Valve's reluctance to discourage volunteers by burdening them with a heavy workload.

It can be understood from the interviews that the participation of individuals outside the community in the VGL process has always been a taboo for both TTC and 23Studios because of their respective non-disclosure agreements signed at the beginning of VGL projects. As can be expected from their paid professional structure, 23Studios employees are even stricter on this point and never consult translators or specialists outside their community about a term or phrase, whereas TTC members may occasionally benefit from such people to find a better equivalent for a problematic term in a VGL process.

The interviews also reflected remarkable differences in terms of community translation as far as both communities' VGL activities are concerned. TTC can be categorized as a hybrid wiki-based and database-driven community translation model because it is overseen by a single moderator on a simple forum, and its technical facilities are provided by the platform on which it functions. In this respect, it constitutes a challenge to the current literature on different community translation models. However, 23Studios has built up its own VGL platform through investment in an office as well as various technological devices and software to create a more confidential and distinct environment, making it a full-fledged community translation environment. It is safe to argue that this significant difference stems from and reflects the differences between the technical facilities available to professional community translation providers and those open to volunteers.

\section{Conclusions}

Translation studies has not remained indifferent to the birth of a new field of AVTnamely, VGL - in the first two decades of the twenty-first century. More and more studies have dealt with the intersection of video games and audiovisual products from both a practical and theoretical perspective. However, translation scholars and researchers in Turkey cannot be said to have paid sufficient attention to VGL when compared to the high number and diversity of studies on VGL in Europe and the US. This is presumably linked to the limited number of Turkish translation scholars interested in this sub-discipline of AVT. Therefore, the present 
transLogos 2020 Vol 3 Issue 2

Sarıül, Semih, and Jonathan Maurice Ross, pp. 1-22

Volunteer vs. Professional Community Translation in

study dealt with community translation processes in volunteer and professional VGL activities within the scope of the STS in Turkey.

The interviews indicated three main similarities between TTC and 23Studios - namely, the role of the project manager, a fairly participatory VGL process, and the approach towards linguistic support from individuals and sources outside the community. However, it was also observed that TTC is somewhat less strict on these matters, in that it sometimes allows its members to select their own tasks or to consult specialists outside the community, albeit occasionally. A more flexible approach on the part of TTC may be attributed to 23Studios members' concerns about detailed non-disclosure agreements compared to those of TTC. In addition, the profit-driven nature of 23Studios' activities may have required them to act more cautiously when it comes to diverging from their standardized community translation process. It was demonstrated in the present study that, as Kelly, Ray, and DePalma (2011) and O'Hagan (2011) have also pointed out, it is problematic to pigeonhole community translation processes within a certain subcategory of translation, be it voluntary-based or for-profit. As far as VGL is concerned, similar steps and implementations might be seen in different online translation communities.

The interviews also opened up a possibly new avenue for future research in community translation due to a clear difference between TTC and 23Studios in terms of the theoretical classification of their VGL activities. When we apply the taxonomy developed by Kelly, Ray, and DePalma (2011), TTC can be said to constitute a hybrid structure, whereas 23Studios is more in line with the theoretical definition in the third category. The difference is likely to result from the financial means of both communities, one of them being a volunteer one, while the other is a for-profit VGL service company. Therefore, both interviews pointed to the need to create more detailed taxonomies that take into account the financial dimensions of the online translation projects carried out in line with community translation practices.

The present study attempted to portray only one aspect of community translation in VGL activities in Turkey and, to this end, analyzed the differences and similarities in community translation processes between volunteer and professional VGL organizations working within the framework of the STS. It does not claim to have offered a comprehensive portrait of all community translation activities in Turkey, as there are people who work voluntarily for various VGL communities outside the STS and for other professional VGL 
transLogos 2020 Vol 3 Issue 2

Sarıül, Semih, and Jonathan Maurice Ross, pp. 1-22

trans Logos

Volunteer vs. Professional Community Translation in

A Translation Studies Journal

Video Game Localization:

(C) Diye Global Communications

The Case of the Steam Translation Server in Turkish diye.com.tr|diye@diye.com.tr

service companies. Future studies may undertake to take a closer look at other community translation activities in Turkish and Turkey, particularly in the field of VGL. 
transLogos $2020 \mathrm{Vol} 3$ Issue 2

Sarıül, Semih, and Jonathan Maurice Ross, pp. 1-22

Volunteer vs. Professional Community Translation in

\section{References}

Diri, Bekir. 2019. "Turkish Issues in Video Game, Web and Mobile Application Localizations." Master's thesis, Istanbul 29 Mayıs University.

Edley, Nigel, and Lia Litosseliti. 2010. "Contemplating Interviews and Focus Groups." In Research Methods in Linguistics, edited by Lia Litosseliti, 155-179. London: Continuum.

Galhardi, Rafael Müller. 2014. "Video Games and Fan Translations: A Case Study of Chrono Trigger." In Fun for All: Translation and Accessibility Practices in Video Games, edited by Carmen Mangiron, Pilar Orero, and Minako O’Hagan, 175-195. Bern: Peter Lang.

Hernández Bartolomé, Ana Isabel, and Gustavo Mendiluce Cabrera. 2005. "New Trends in Audiovisual Translation: The Latest Challenging Modes." Miscelánea 31:89-104. https://dialnet.unirioja.es/servlet/articulo?codigo=2010052.

Jiménez Crespo, Miguel A. 2017. Crowdsourcing and Online Collaborative Translations: Expanding the Limits of Translation Studies. Amsterdam: John Benjamins.

Karagöz, Selahattin. 2019. “Amatörler, Uzmanlar, Kâşifler: Türkiye'de Video Oyun Çevirileri ve Yerelleştirme Süreci.” [Amateurs, experts, explorers: Video game localization practices in Turkey.] PhD diss., Yıldız Technical University.

Kelly, Nataly, Rebecca Ray, and Donald A. DePalma. 2011. "From Crawling to Sprinting: Community Translation Goes Mainstream." Linguistica Antverpiensia 10:75-94. https://lans-tts.uantwerpen.be/index.php/LANS-TTS/article/view/278.

Koelewijn, Cees. 2015. "Of Stolen Boats and Antialiasing: Translating Rockstar's Video Game Grand Theft Auto V.” Master's thesis, Utrecht University.

Muñoz Sánchez, Pablo. 2009. "Video Game Localisation for Fans by Fans: The Case of Romhacking." The Journal of Internationalization and Localization 1 (1): 168-185. doi:10.1075/jial.1.07mun.

Odacıŏglu, Cem, and Şaban Köktürk. 2015. "Wolfenstein: The Old Blood Oyununun Türkçe Yerelleştirilmiş Versiyonunda Benimsenen Çeviri Yaklaşımları ve Bunun Oynanabilirlik Düzeyine Katkısı." [The adopted translation approaches in the Turkish localized version of The Wolfenstein: Old Blood and its contribution to the game play level.] Journal of History School, no. 23, 303-318. doi:10.14225/Joh760.

O’Hagan, Minako. 2011. "Community Translation: Translation as a Social Activity and Its Possible Consequences in the Advent of Web 2.0 and Beyond." Linguistica Antverpiensia 10:11-23. https://lans-tts.ua.ac.be/index.php/LANS-TTS/article/view/275.

2012. "Translation as the New Game in the Digital Era." Translation Spaces 1 (1): 123-141. doi:10.1075/ts.1.06oha. 
transLogos 2020 Vol 3 Issue 2

Sarıül, Semih, and Jonathan Maurice Ross, pp. 1-22

Volunteer vs. Professional Community Translation in

O’Hagan, Minako, and Carmen Mangiron. 2013. Game Localization: Translating for the Global Digital Entertainment Industry. Amsterdam: John Benjamins.

Öncü Yılmaz, Tutku, and Emre Canbaz. 2019. "Hikâye Odaklı Video Oyunlarda Çevirinin Rolü: The Last of Us Video Oyunu Üzerine Bir Değerlendirme." [The role of translation in story driven video games: An evaluation of The Last of Us.] Journal of Translation Studies, no. 26, 77-103. https://dergipark.org.tr/en/download/article-file/635908.

Önen, Seçkin İlke. 2018. "Approaches and Strategies to Cope with the Specific Challenges of Video Game Localization.” Master's thesis, Hacettepe University.

Pérez González, Luis. 2009. “Audiovisual Translation.” In Routledge Encyclopedia of Translation Studies, edited by Mona Baker and Gabriela Saldanha, 13-20. London: Routledge.

Petrů, Jiř́. 2011. "Video Game Translation in the Czech Republic: From Fan Era to Professionalism.” Master's thesis, Masaryk University.

Pym, Anthony. 2011. "Translation Research Terms: A Tentative Glossary for Moments of Perplexity and Dispute." In Translation Research Projects, edited by Anthony Pym, 3:75-110. Tarragona: Intercultural Studies Group.

Saldanha, Gabriela, and Sharon O'Brien. 2013. Research Methodologies in Translation Studies. Manchester: St. Jerome.

Sarıül, Semih. 2020. "Turkish Translation in the Steam Translation Server: Two Case Studies on Video Game Localisation.” PhD diss., Boğaziçi University.

Zan, Arman. 2018. "Domestication and Foreignization in the Turkish Translation of Video Games." Master's thesis, Hacettepe University. 